\title{
PERENCANAN MATERIAL PRODUK SANDAL DENGAN METODE MATERIAL REQUIREMENT PLANNING (MRP)
}

\author{
Syahreen Nurmutia \\ Dosen Teknik Inndustri Universitas Pamulang \\ syahreen23@gmail.com
}

\begin{abstract}
ABSTRAK
Analisis Perencanaan Kebutuhan Bahan Baku Sandal Spon Polos Menggunakan Metode Material Requirement Planning (MRP) Di Identic Footwear untuk membantu perusahaan dalam melakukan perencanaan kebutuhan bahan baku secara efektif dan efisien. Hasil dari perhitungan metode peramalan tersebut yang terpilih adalah metode peramalan Exponential Smoothing karena memiliki tingkat keakurasian yang tinggi. dengan Jadwal Induk Produksi diketahui kebutuhan untuk eva spon $12 \mathrm{~mm}$ sebanyak 32 lembar, teli webbing $1253 \mathrm{~m}$, dan label merek 1566 sebanyak pieces. Perencanaan untuk kebutuhan bahan baku dengan metode MRP menggunakan dengan teknik lot sizing, dimana teknik-teknik lot sizing yang digunakan adalah teknik Economic Order Quantity (EOQ), Periode Order Quantity (POQ), dan Lot For Lot (LFL). Berdasarkan hasil perhitungan yang dilakukan penulis, teknik Periode Order Quantity (POQ) menghasilkan total biaya persediaan yang paling kecil dengan

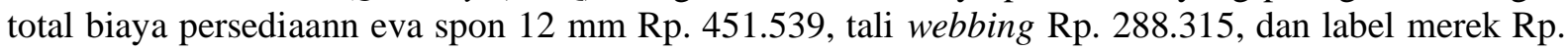
187.519.
\end{abstract}

Kata Kunci: Peramalan, MRP, Lot Sizing,

\section{PENDAhULUAN}

Perkembangan perekonomian saat ini semakin berkembang sangat pesat, di iringi dengan kemajuan perkembangan Teknologi yang semakin canggih. Hal ini mengakibatkan persaingan antar perusahaan pun semakin ketat. Dengan adanya persaingan yang semakin ketat ini perusahaan besar atau kecil perlu menetapkan pengendalian terhadap persediaan bahan baku secara tepat untuk mencapai tujuan yang diinginkan, sehingga perusahaan akan bisa bertahan dan berkembang menghadapi persaingan yang akan semakin meningkat secara terus menerus. Apabila tidak tersedianya persediaan, maka suatu saat perusahaan akan mengalami kesulitan untuk memenuhi kebutuhan konsumen yang meminta atau memerlukan barang yang dihasilkan.

Perusahaan haruslah dapat menjaga persediaan yang cukup agar kegiatan produksi dapat berjalan dengan lancar dan efisien. Oleh karena itu penting bagi perusahaan untuk mengadakan pengawasan atau pengendalian persediaan, karena kegiatan ini dapat membantu agar terciptanya tingkat efisiensi penggunaan bahan baku.

Identic Footwear merupakan perusahaan yang bergerak dibidang manufaktur yang

kegiatan utamanya adalah memproduksi sendal. Pada Identic Footwear yang masih berbentuk industri perumahan penting adanya persediaan untuk dapat mengembangkan perusahaan agar dapat menjaga kelangsungan hidup perusahaan. Selama ini Identic Footwear menggunakan perkiraan data penjualan periode sebelumnya dalam melaksanakan perencanaan dan penjadwalan produksi tanpa menggunakan metode standar. Sehingga sering mendapatkan masalah karena kelebihan dan kekurangan bahan baku. Data stok pemasukan dan penggunaan bahan baku eva spon hitam 12 $\mathrm{mm}$, tali webbing, dan label merek pada bulan Agustus 2017 sampai Juli 2018 di Identic Footwear pada Tabel 1.1, Data Bahan Baku Eva Spon $12 \mathrm{~mm}$ dan Tali Webbing dan Tabel 1.2 Data Bahan Baku Label Merek berikut:

Tabel 1.1 Data Bahan Baku Eva Spon 12 mm dan Tali Webbing

\begin{tabular}{|c|r|r|r|r|}
\hline \multirow{2}{*}{ Bulan } & \multicolumn{2}{|c|}{ Eva Spon $\mathbf{1 2} \mathbf{~ m m}$} & \multicolumn{2}{c|}{ Tali Webbing $(\mathbf{m})$} \\
\cline { 2 - 5 } & Masuk & $\begin{array}{c}\text { Penggu } \\
\text { naan }\end{array}$ & Masuk & $\begin{array}{c}\text { Penggu } \\
\text { naan }\end{array}$ \\
\hline Stok diketahui & 3,04 & & 42,4 & \\
\hline Agustus 2017 & 18 & 8,44 & 250 & 112,2 \\
\hline September 2017 & 0 & 6,02 & 0 & 49,4 \\
\hline Oktober 2017 & 18 & 7,48 & 0 & 99,3 \\
\hline
\end{tabular}




\begin{tabular}{|l|r|r|r|r|}
\hline November 2017 & 0 & 5,73 & 300 & 76,4 \\
\hline Desember 2017 & 0 & 6,61 & 0 & 88,1 \\
\hline Januari 2018 & 12 & 10,85 & 100 & 144,4 \\
\hline Februari 2018 & 9 & 8,43 & 0 & 112,6 \\
\hline Maret 2018 & 15 & 6,04 & 150 & 80,1 \\
\hline April 2018 & 0 & 7,83 & 0 & 104,6 \\
\hline Mei 2018 & 18 & 9,93 & 300 & 132,2 \\
\hline Juni 2018 & 0 & 6,04 & 0 & 80,3 \\
\hline Juli 2018 & 0 & 8,74 & 0 & 116,5 \\
\hline Total & 93,4 & 92,14 & 1142 & 1227,1 \\
\hline
\end{tabular}

(Sumber: Identic Footwear)

Tabel 1.2 Data Bahan Baku Label Merek

\begin{tabular}{|l|r|r|}
\hline \multicolumn{1}{|c|}{ Bulan } & \multicolumn{2}{c|}{ Label Merek } \\
\cline { 2 - 3 } & \multicolumn{1}{|c|}{ Masuk } & Penggunaan \\
\hline Stok diketahui & 480 & \\
\hline Agustus 2017 & 0 & 140 \\
\hline September 2017 & 0 & 100 \\
\hline Oktober 2017 & 0 & 124 \\
\hline November 2017 & 300 & 95 \\
\hline Desember 2017 & 0 & 110 \\
\hline Januari 2018 & 0 & 180 \\
\hline Februari 2018 & 200 & 140 \\
\hline Maret 2018 & 200 & 100 \\
\hline April 2018 & 0 & 130 \\
\hline Mei 2018 & 400 & 165 \\
\hline Juni 2018 & 0 & 100 \\
\hline Juli 2018 & 0 & 145 \\
\hline Total & 1580 & 1529 \\
\hline
\end{tabular}

(Sumber: Identic Footwear)

Dari data Tabel 1.1 dan Tabel 1.2 di atas jika total masuk bahan baku dikurang total penggunaan bahan baku dapat diketahui untuk eva spon $12 \mathrm{~mm}$ : 93,04 - 92,14 =0,9, tali webbing: $1142,4-1227,1=-84,7$, dan Label Merek: $1580-1529=51$. Maka dari hasil perhitungan tersebut pada bulan Agutus 2017 sampai dengan Juli 2018 untuk bahan baku eva spon $12 \mathrm{~mm}$ mengalami kelebihan bahan baku sebanyak $0,9 \quad \mathrm{~m}^{2}$, untuk tali webbing mengalami kekurangan sebanyak $84,7 \mathrm{~m}$, dan label merek mengalami kelebihan sebanyak 51 pieces.

Kendala-kendala tersebut, terutama yang terkait dengan bahan baku, dapat diatasi salah satunya dengan melakukan perencanaan produksi yang baik melalui Material Requirement Planning (MRP). Penerapan MRP dapat memberikan informasi kepada perusahaan mengenai jumlah produksi optimum yang mampu dicapai sehingga sesuai dengan sumber daya yang dimiliki agar lebih efisien (Herjanto, 2008:276).

\section{LANDASAN TEORI}

\section{A. Proses MRP}

Russel dan Taylor (2003) menyebutkan bahwa penerapan suatu MRP memiliki proses yang terdiri atas empat langkah utama, yaitu (1) menyusun BOM, (2) menghitung kebutuhan bersih bahan baku (net requirement), (3) melakukan lot sizing, dan (4) menyusun time-phasing requirement. Proses ini dilakukan berulang kali, merinci setiap struktur produk hingga semua komponen dibuatkan jadwalnya..

\section{B. Model penentuan Lot Sizing}

Lot sizing adalah suatu kegiatan untuk menentukan jumlah unit yang akan dipesan (Haming dan Nurnajamuddin, 2014:36). Dengan keputusan menentukan ukuran lot merupakan suatu teknik dalam menentukan ukuran lot tersebut (Heizer dan Render, 2015:654)

\section{Total Penentuan}

Biaya variabel persediaan lazim disebut incremental cost. Dengan demikian biaya variabel total (Total Incrementas Cost, TIC) dapat ditulis dalam persamaan berikut (Haming dan Nurnajamuddin, 2014:9):

\section{BV Persediaan $(T I C)=$ Biaya Pemesanan + Biaya Penyimpanan}

\section{METODE TEKNIK PENGUKURAN}

Metode yang digunakan adalah Material Requirement Planning (Mrp)

Produk Bahan Baku

$$
\text { "Sandal" }
$$

Analisis Perencanaan Kebutuhan Bahan Baku Sandal Spon Polos Menggunakan Metode Material Requirement Planning (MRP) Di Identic Footwear

Metode Pengumpulan Data

1. Data Primer $=$ Wawancara

2. Data Sekunder $=$ Dokumen Perusahaan

$\downarrow$

1. Data Persediaan dan Penjualan Identic Footwear Agustus 2017 sampai Juli 2018.

2. Peramalan (Forecasting)

3. Bill Of Material

4. Jadwal Induk Produksi (JP)

Hasil perhitungan

(Sumber: Penulis)

Gambar 3.1 Flowchart Penelitian 


\section{HASIL DAN PEMBAHASAN}

\section{A. Data Penjualan}

Data penjualan sandal spon hitam pada Agustus 2017 sampai dengan Juli 2018 tesaji pada Tabel 4.1 berikut ini:

Tabel 4.1 Data Penjualan Sandal Spon Polos

\begin{tabular}{|l|c|}
\hline \multicolumn{1}{|c|}{ Bulan } & Penjualan \\
\hline Agustus 2017 & 138 \\
\hline September 2017 & 98 \\
\hline Oktober 2017 & 124 \\
\hline November 2017 & 94 \\
\hline Desember 2017 & 108 \\
\hline Januari 2018 & 178 \\
\hline Februari 2018 & 139 \\
\hline Maret 2018 & 98 \\
\hline April 2018 & 130 \\
\hline Mei 2018 & 165 \\
\hline Juni 2018 & 100 \\
\hline Juli 2018 & 144 \\
\hline Total & 1516 \\
\hline
\end{tabular}

(Sumber: Identic Footwear, Agustus 2018)

Dari tabel data diatas adalah hasil penjualan sandal spon polos di Identik Footwear dari Bulan Agustus 2017 sampai dengan Juli 2018.

\section{B. Data Bill Of Material}

Data Bill Of Material (BOM) untuk membuat satu pasang produk sandal spon polos adalah sebagai berikut:

Tabel 4.2 Data Bill Of Material (BOM) Sandal Spon Polos

\begin{tabular}{|c|l|c|}
\hline No & Jenis Bahan baku & $\begin{array}{c}\text { Penggunaan } \\
\text { Bahan Baku }\end{array}$ \\
\hline 1 & Eva Spon $12 \mathrm{~mm}$ & $0,06 \mathrm{~m}^{2}$ \\
\hline 2 & Tali Webbng & $0,8 \mathrm{~m}$ \\
\hline 3 & Label Merek & 1 pieces \\
\hline
\end{tabular}

(Sumber: Identic Footwear, Agustus 2017)

\section{Pengolahan Data}

Dalam pengolahan data yang diambil adalah sebagai berikut:

\section{Peramalan Penjualan}

Hasil peramalan Moving Average dengan periode rata-rata 3 bulan dengan rumus perhitungan untuk bulan November

a. $\mathrm{MA}=((138+98+124) / 3=120$ dan seterusnya, Weighted Moving Average dengan periode rata-rata 3 bulan dan diberikan bobot bulan agustus 1 , bobot bulan september 2, bobot bulan oktober
3 dengan rumus perhitungan peramalan bulan November

b. $\mathrm{WMA}=((138 \times 1)+((98 \times 2)+(124 \times 3)) / 6=$ 117,67 dan seterusnya, Exponential Smoothing dengan alpha $\mathrm{a}=2 /(12+1)=$ 0,15 karena bulan Agustus tidak memiliki peramalan maka aktual permintaan bulan Agustus menjadi peramalan bulan September untuk rumus perhitungan bulan Oktober

c. $\mathrm{ES}=138+0,15 \cdot(98-138)=132$. Data parameter-parameter kesalahan Mean Absolute Deviation dan Mean Squared Error dan Mean Absolute Percentage Error seperti pada Tabel 4.7 berikut:

Dari hasil peramalan penjualan diatas dapat dilihat pada tabel 4.7 Akurasi Metode Peramalan dibawah ini:

Tabel 4.7 Akurasi Metode Peramalan

\begin{tabular}{|l|c|c|c|}
\hline $\begin{array}{c}\text { Metode } \\
\text { Peramalan }\end{array}$ & MAD & MSE & MAPE \\
\hline $\begin{array}{l}\text { Moving } \\
\text { Average }\end{array}$ & 27,59 & 1172,46 & $0,22 \%$ \\
\hline $\begin{array}{l}\text { Weighted } \\
\text { Moving } \\
\text { Average }\end{array}$ & 28,69 & 1355,21 & $0,23 \%$ \\
\hline $\begin{array}{l}\text { Exponential } \\
\text { Smoothing }\end{array}$ & 26,27 & 942,97 & $0,22 \%$ \\
\hline
\end{tabular}

(Sumber: Pengolahan Data Penulis)

Berdasarkan hasil pengujian akurasi pada Tabel 4.7 menunjukkan bahwa peramalan sandal spon polos yang memiliki akurasi tertinggi adalah Exponential Smoothing karena memiliki nilai MAD, MSE, dan MAPE yang paling kecil.

\section{Bill Of Material}

Selain catatan pada persediaan material, dalam proses membuat MRP (Material Planning Requerement) yang harus diperhatikan adalah menentukan material yang ada. MRP mdapat menentukan Bill Of Material (BOM). Untuk penjabaran dari BOM ini dibuat untuk produk sandal spon polos yang dapat dilihat pada Tabel 4.2. Alur Bill Of Material dapat dilihat pada Gambar 4.2 berikut ini:

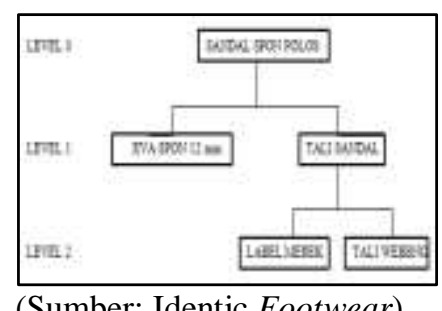

(Sumber: Identic Footwear) Gambar 4.2 Bill Of Material 


\section{Jadwal Induk Produksi}

Dari data peramalan dan pada Tabel 4.8 dapat direncanakan kebutuhan eva spo $8 \mathrm{~m}$, tali webbng, dan label merek untuk Agustus 2018 sampai dengan Juli 2019 yang dapat dijabarkan pada Tabel 4.10 Peramalan kebutuhan Baku berikut ini:

Tabel 4.10 Peramalan Kebutuhan Bahan Baku

\begin{tabular}{|c|c|c|c|c|}
\hline \multirow[b]{2}{*}{ Bulan } & \multirow[b]{2}{*}{$\begin{array}{l}\text { Peramalan } \\
\text { permintaan }\end{array}$} & \multicolumn{3}{|c|}{$\begin{array}{c}\text { Kebutuhan bersih bahan } \\
\text { baku }\end{array}$} \\
\hline & & $\begin{array}{c}\text { Eva } \\
\text { spon } \\
\mathbf{1 2} \\
\mathbf{m m} \\
\left(\mathbf{m}^{2}\right)\end{array}$ & $\begin{array}{c}\text { Tali } \\
\text { webbng } \\
\text { (m) }\end{array}$ & $\begin{array}{c}\text { Label } \\
\text { merek } \\
\text { (pieces) }\end{array}$ \\
\hline $\begin{array}{l}\text { Agustus } \\
2018\end{array}$ & 138 & 8,28 & 110,4 & 138 \\
\hline $\begin{array}{l}\text { September } \\
2018\end{array}$ & 138 & 8,28 & 110,4 & 138 \\
\hline $\begin{array}{c}\text { Oktober } \\
2018\end{array}$ & 132 & 7,92 & 105,6 & 132 \\
\hline $\begin{array}{l}\text { November } \\
2018\end{array}$ & 131 & 7,86 & 104,8 & 131 \\
\hline $\begin{array}{c}\text { Desember } \\
2018 \\
\end{array}$ & 125 & 7,5 & 100 & 125 \\
\hline $\begin{array}{c}\text { Januari } \\
2019 \\
\end{array}$ & 123 & 7,38 & 98,4 & 123 \\
\hline $\begin{array}{c}\text { Februari } \\
2019\end{array}$ & 131 & 7,86 & 104,8 & 131 \\
\hline $\begin{array}{c}\text { Maret } \\
2019 \\
\end{array}$ & 132 & 7,92 & 105,6 & 132 \\
\hline $\begin{array}{l}\text { April } \\
2019 \\
\end{array}$ & 127 & 7,62 & 101,6 & 127 \\
\hline Mei 2019 & 128 & 7,68 & 102,4 & 128 \\
\hline Juni 2019 & 133 & 7,98 & 106,4 & 133 \\
\hline Juli 2019 & 128 & 7,68 & 102,4 & 128 \\
\hline Total & 1566 & 93,96 & 1252,8 & 1566 \\
\hline Rata-rata & 131 & 7,83 & 104,4 & 131 \\
\hline
\end{tabular}

(Sumber: Pengolahan Data Penulis)

Data Tabel 4.10 diatas merupakan data kebutuhan bersih bahan baku hasil dari JIP $=$ (Peramalan permintaan $\mathrm{x}$ Bill $O f$ Material).

\section{Biaya Pesan dan Biaya Simpan}

Pemesanan melalui telepon genggam ratarata membutuhkan waktu 3 menit. Biaya tarif telepon sebesar Rp. 799,-- per menit.

Tabel 4.11 Biaya Pemesanan

\begin{tabular}{|l|c|c|c|}
\hline $\begin{array}{l}\text { Jenis } \\
\text { Bahan } \\
\text { Baku }\end{array}$ & $\begin{array}{c}\text { Biaya } \\
\text { telepon }\end{array}$ & $\begin{array}{c}\text { Biaya } \\
\text { Transporta } \\
\text { si }\end{array}$ & Total \\
\hline $\begin{array}{l}\text { Eva } \\
\begin{array}{l}\text { Spon } 12 \\
\text { mm }\end{array}\end{array}$ & Rp. 2.397 & Rp. 120.000 & Rp. 122.397 \\
\hline $\begin{array}{l}\text { Tali } \\
\text { webbng }\end{array}$ & Rp. 2.397 & Rp. 80.000 & Rp. 82.397 \\
\hline
\end{tabular}

\begin{tabular}{|l|r|r|r|}
\hline $\begin{array}{l}\text { Label } \\
\text { Merek }\end{array}$ & Rp. 2.397 & Rp. 35.000 & Rp. 37.397 \\
\hline
\end{tabular}

(Sumber: Identic Footwear, Agustus 2018)

Biaya yang dikeluarkan perusahaan untuk penerangan digudang bahan baku sebesar Rp. 50.000,- per bulan.

Tabel 4.12 Biaya Penyimpanan

\begin{tabular}{|l|c|c|c|l|}
\hline $\begin{array}{c}\text { Jenis } \\
\text { Bahan } \\
\text { Baku }\end{array}$ & $\begin{array}{c}\text { Jumlah } \\
\text { persedia } \\
\text { an } \\
\text { /tahun }\end{array}$ & $\begin{array}{c}\text { Biaya } \\
\text { Penyimpana } \\
\text { n/tahun }\end{array}$ & $\begin{array}{c}\text { Biaya } \\
\text { Penyimpan } \\
\text { an /bulan }\end{array}$ & $\begin{array}{c}\text { Biaya } \\
\text { penyimpan } \\
\text { an /unit }\end{array}$ \\
\hline $\begin{array}{l}\text { Eva } \\
\text { spon } \\
12 \mathrm{~mm}\end{array}$ & $\begin{array}{c}32 \\
\text { lembar/3 } \\
\mathrm{m}^{2}\end{array}$ & Rp. 600.000 & Rp. 50.000 & $\begin{array}{l}\text { Rp. } \\
1.562,5\end{array}$ \\
\hline $\begin{array}{l}\text { Tali } \\
\text { webbn } \\
\text { g }\end{array}$ & $1253 \mathrm{~m}$ & Rp. 600.000 & Rp. 50.000 & Rp. 39,9 \\
\hline $\begin{array}{l}\text { Label } \\
\text { merek }\end{array}$ & $\begin{array}{c}1566 \\
\text { pieces }\end{array}$ & Rp. 600.000 & Rp. 50.000 & Rp. 31,9 \\
\hline
\end{tabular}

(Sumber: Identic Footwear, Agustus 2018)

\section{Material Requirement Planning}

a. Perhitungan MRP tekniik EOQ

$\mathrm{EOQ}=\sqrt{\frac{2 A D}{H}}$

Dimana:

D : permintaan rata-rata per periode

A : biaya pesan (order cost)

$\mathrm{H}$ : biaya penyimpanan (holding cost)

1) Eva Spon $12 \mathrm{~mm}$

Catatan persediaan $\quad: 0,9 \mathrm{~m}^{2}$

Rata-rata permintaan (D) : 7,83 $\mathrm{m}^{2}$

Biaya pesan (A) :Rp. $122.397 /$ pesan

Biaya simpan $(\mathrm{H}) \quad$ : Rp. $1562,5 / 3 \mathrm{~m}^{2}$

$\mathrm{EOQ}=\sqrt{\frac{2 A D}{H}} \quad \mathrm{EOQ}=\sqrt{\frac{2 .(122.397) \cdot(7,83)}{1562,5}}$

$\mathrm{EOQ}=35,084 \mathrm{~m}^{2} /$ pesan dibulatkan ke $36 \mathrm{~m}^{2}$ (diketahui karena satu lembar eva spon $12 \mathrm{~mm}$ adalah $3 \mathrm{~m}^{2}$ )

Pemesanan yang dilakukan selama setahun adalah 3 kali pesan, sedangkan untuk penyimpanan eva spon $12 \mathrm{~mm}$ selama setahun hasil dari perhitungan EOQ adalah 222,84 $\mathrm{m}^{2}$, karena biaya hitungan penyimpanan perlembar maka penyimpanan selama setahun adalah $222,84 \mathrm{~m}^{2}: 3 \mathrm{~m}^{2}=74$ lembar $/ 3 \mathrm{~m}^{2}$.

Biaya pemesanan:

Rp. 122.397 x 3 = Rp. 367.191

Biaya penyimpanan:

Rp. 1562.5 x $74=$ Rp. 115.625

Total:

Rp. $367.191+$ Rp. $115.625=$ Rp. 482.816

2) Tali webbing

Catatan persediaan $\quad: 58,9 \mathrm{~m}$ 
Rata-rata permintaan (D) : 104,4 m

Biaya per pesan (A) : Rp. 82.397

Biaya simpan $(\mathrm{H}) \quad$ : Rp. $39,9 / \mathrm{m}$

$\mathrm{EOQ}=\sqrt{\frac{2 A D}{H}} \mathrm{EOQ}=\sqrt{\frac{2 .(82397) \cdot(104,4)}{39,9}}$

$\mathrm{EOQ}=656,6 \mathrm{~m}$ dibulatkan $\mathrm{ke} 657 \mathrm{~m} /$ pesan

Pemesanan yang dilakukan selama setahun adalah 2 kali pesan, sedangkan untuk penyimpanan tali webbing selama setahun hasil dari perhitungan EOQ adalah $4320 \mathrm{~m}$.

Biaya pemesanan:

Rp. 82.397 x 2 = Rp. 164.794

Biaya penyimpanan:

Rp. 39,9 x $4320=$ Rp. 172.368

Total:

Rp. 164.794 + Rp. 172.368 = Rp. 337.162

3) Label merek

Catatan persediaan : 88 pieces

Rata-rata permintaan (D) : 131 pieces

Biaya per pesan (A) : Rp. 37.397

Biaya simpan $(\mathrm{H}) \quad$ : Rp. 31,9/pieces

$\mathrm{EOQ}=\sqrt{\frac{2 A D}{H}} \quad \mathrm{EOQ}=\sqrt{\frac{2 .(37397) \cdot(131)}{31,9}}$

$\mathrm{EOQ}=554,2$ dibulatkan 554 pieces $/$ pesan

Pemesanan yang dilakukan selama setahun adalah 3 kali pesan, sedangkan total untuk penyimpanan label merek selama setahun hasil dari perhitungan EOQ adalah 3527 pieces.

Biaya pemesanan:

Rp. 37.397 x $3=$ Rp. 112.191

Biaya penyimpanan :

Rp. $31,9 \times 3527=$ Rp. 112.511

Total:

Rp. $112.191+$ Rp. 112.511

$=$ Rp. 224.702

b. Perhitunngan MRP teknik POQ

$\mathrm{POQ}=\sqrt{\frac{2 . S}{D . H}}$

Dimana:

D : rata-rata permintaan per periode

$\mathrm{S}$ : biaya pesan

$\mathrm{H}$ : biaya penyimpanan

1) Eva spon $12 \mathrm{~mm}$

Catatan persediaan $\quad: 0,9 \mathrm{~m}^{2}$

Permintaan per periode (D) $: 7,83 \mathrm{~m}^{2}$

Biaya pesan (S) : Rp. 122.397

Biaya penyimpanan $(\mathrm{H}) \quad$ : Rp. 1.562,5 / 3 $\mathrm{m}^{2}$

$\mathrm{POQ}=\sqrt{\frac{2 . S}{D . H}} \quad \mathrm{POQ}=\sqrt{\frac{2.122397}{7,83.1562,5}}$
POQ $=4$, jadi pemesanan dilakukan setiap 4 periode.

Pemesanan selama satu tahun untuk eva spon $12 \mathrm{~mm}$ adalah 3 kali pesan, sedangkan untuk penyimpanan eva spon $12 \mathrm{~mm}$ selama satu tahun adalah 162,84 $\mathrm{m}^{2}$, karena perhitungan biaya penyimpanan perlembar maka penyimpanan eva spon $12 \mathrm{~mm}$ selama setahun adalah 162,84 $\mathrm{m}^{2}: 3 \mathrm{~m}^{2}=54$ lembar $13 \mathrm{~m}^{2}$.

Biaya pemesanan:

Rp. 122.379 x 3 = Rp. 367.191

Biaya penyimpanan:

Rp. 1562,5 x $54=\operatorname{Rp} 84.375$

Total:

Rp. $367.191+$ Rp. $84.375=$ Rp. 451.566

2) Tali webbing

Catatan persediaan $\quad: 58,9 \mathrm{~m}$

Permintaan per periode (D) $\quad: 104,4 \mathrm{~m}$

Biaya pesan (S) : Rp. 82.397

Biaya penyimpanan $(\mathrm{H}) \quad$ : Rp. 39,9/m

$\mathrm{POQ}=\sqrt{\frac{2 . S}{D . H}} \mathrm{POQ}=\sqrt{\frac{2.82397}{104,4.39,9}}$

$\mathrm{POQ}=6,28$ (dibulatkan) ke 6 , jadi pemesanan dilakukan setiap 6 periode.

Pemesanan selama satu tahun untuk tali webbing adalah 2 kali pesan, sedangkan untuk penyimpanan tali webbing selama satu tahun adalah $3088 \mathrm{~m}$.

Biaya pemesanan:

Rp. 82.379 x 2 = Rp. 164.794

Biaya penyimpanan:

Rp. 39,9 × $3088=\mathrm{Rp} 123.211$

Total:

Rp. 164.794 + Rp. 123.211

$=$ Rp. 288.005

3) Label merek

Catatan persediaan : 88 pieces

Permintaan per periode (D) : 131 pieces

Biaya pesan (S) : Rp. 37.397

Biaya penyimpanan $(\mathrm{H}) \quad$ : Rp. 31,9/pieces

POQ $=\sqrt{\frac{2 . S}{D . H}} \quad$ POQ $=\sqrt{\frac{2.37397}{131.31,9}}$

$\mathrm{POQ}=4,22$ (dibulatkan) ke 4, jadi pemesanan dilakukan setiap 4 periode.

Pemesanan selama satu tahun untuk label merek adalah 3 kali pesan, sedangkan untuk penyimpanan label merek selama satu tahun adalah 2354 pieces.

Biaya pemesanan:

Rp. 37.379 x 3 = Rp. 112.191

Biaya penyimpanan: 
Rp. 31,9 x $2354=\operatorname{Rp} 75.093$

Total:

Rp. $112.191+$ Rp. 75.093

$=$ Rp. 187.284

c. Perhitungan MRP teknik LFL

Pada metode ini yang paling sederhana dan muda dimengerti, besar pemesanan adalah sama dengan kebutuhan bersih atau mendekati kebutuhan bersih yang harus di penuhi pada periode yang bersangkutan.

1. Eva spon $12 \mathrm{~mm}$

Karena per lembar eva spon $12 \mathrm{~mm}$ adalah $3 \mathrm{~m}^{2}$ maka setiap pemesanan yang dilakukan per periode adalah berkelipatan 3 untuk menutupi kebutuhan bersih bahan baku.

Pemesanan selama satu tahun untuk eva spon $12 \mathrm{~mm}$ adalah 12 kali pesan, sedangkan untuk penyimpanan eva spon $12 \mathrm{~mm}$ selama satu tahun adalah $18,84 \mathrm{~m}^{2}$, karena perhitungan biaya penyimpanan perlembar maka penyimpanan eva spon $12 \mathrm{~mm}$ selama setahun adalah $18,84 \mathrm{~m}^{2}: 3 \mathrm{~m}^{2}=6 \mathrm{lembar} / 3 \mathrm{~m}^{2}$.

Biaya pemesanan:

Rp. 122.379 x $12=$ Rp. 1.468 .764

Biaya penyimpanan:

Rp. 1562,5 × $6=\operatorname{Rp} 9.375$

Total:

Rp. 1.468 .764 + Rp. $9.375=$ Rp. 1.478 .139

2. Tali webbing

Pemesanan selama satu tahun untuk tali webbing adalah 12 kali pesan, sedangkan untuk penyimpanan label merek selama satu tahun adalah 5,1 m dibulatkan menjadi $5 \mathrm{~m}$.

Biaya pemesanan:

Rp. 82.379 x $12=$ Rp. 988.764

Biaya penyimpanan:

Rp. 39,9 × $5=$ Rp. 200

Total:

Rp. $988.764+$ Rp. $200=$ Rp. 988.964

\section{Label merek}

Pemesanan selama satu tahun untuk label merek adalah 12 kali pesan, sedangkan untuk penyimpanan label merek tidak memiliki persediaan.

Biaya pemesanan:

Rp. 37.379 x $12=$ Rp. 448.764

Biaya penyimpanan:

Rp. 31,9 x $0=$ Rp. 0

Total:

Rp. $448.764+$ Rp. $0=$ Rp. 448.764

\section{Biaya Total Bahan Baku}

Teknik EOQ dan POQ pada teknik LFL adalah setiap rangkaian material yang dapat menghasilkan biaya pemesanan unggul dalam menghasilkan biaya penyimpanan terendah untuk eva spon $12 \mathrm{~mm}$, dan tali webbing, bahkan sampai nol rupiah untuk penyimpanan label merek. Lebih jelasnya dilihat pada tabel 4.23 berikut:

Tabel 4.23 Perbandingan Biaya dari Ketiga Lot Sizing

\begin{tabular}{|c|c|c|}
\hline \multicolumn{3}{|c|}{ Biaya total bahan baku (Rp) } \\
\hline EOQ & POQ & LFL \\
\hline 482.816 & 451.539 & 1.478 .139 \\
\hline 337.162 & 288.314 & 988.964 \\
\hline 224.702 & 187519 & 448.764 \\
\hline
\end{tabular}

(Sumber: Hasil Pengolahan Data, 2018)

Berdasarkan perbandingan biaya dari ketiga lot sizing yang ditunjukan pada Tabel 4.23 dapat ditarik kesimpulan bahwa pengadaan untuk seluruh komponen bahan baku optimum jika menggunakan teknik POQ karena metode POQ memiliki biaya total bahan baku terendah.

\section{Skedul Material Requirement Planning}

Skedul berdasarkan teknik POQ karena memimiliki biaya total bahan baku yang terendah. Diketahui Gross Requirement dari ketiga bahan baku selalu terpenuhi maka Net Requirement dan Planned Order Receipts kosong selama 12 periode.

\section{PENUTUP}

\section{A. Kesimpulan}

Diperoleh beberapa kesimpulan, berdasarkan penelitian yang telah dilakukan sebagai berikut :

1. Hasil dari JIP jumlah bahan baku utama untuk produk sandal spon polos untuk satu tahun dibutuhkan eva spon $12 \mathrm{~mm}$ sebanyak 32 lembar, tali webbing dibutuhkan sepanjang $1253 \mathrm{~m}$, dan untuk label merek dibutuhkan sebanyak 1566 pieces. Ramalan permintaan dibuat dengan metode Exponetial Smoothing. Metode ini terpilih karena memiliki tingkat keakurasian yang baik untuk produk yang 
tidak mempunyai pola trend dan pola musiman. Dengan dibuatkannya JIP memudahkan perusahaan untuk memperkirakan jumlah bahan baku yang dibutuhkan dalam memenuhi ramalan permintaan dan perusahaan dapat memperkirakan jumlah biaya yang diperlukan dalam satu tahun tersebut.

2. Dari hasil pemilihan MRP teknik POQ yang mempunyai biaya bahan baku paling efisien dengan menghitung interval pemesanan yang menentukan jumlah kuantitas optimum untuk menghasilkan pemesanan ekonomis. Metode ini dipakai perusahaan untuk memperkirakan pemesanan bahan baku untuk eva spon 12 mm sebanyak 3 kali, untuk tali webbing sebanyak 2 kali, dan untuk label merek sebanyak 3 kali. Biaya total bahan baku hasil dari teknik EOQ untuk eva spon 12 mm Rp. 482.816, tali webbing Rp. 337.162, dan label merek Rp. 224.702, teknik POQ untuk eva spon $12 \mathrm{~mm}$ Rp. 451.566, tali webbing Rp. 288.005, dan label merek Rp. 187.284, teknik LFL untuk eva spon $12 \mathrm{~mm}$ Rp. 1.478.139, tali webbing Rp. 988.964, dan label merek Rp. 448.764. Maka hasil pemesanan bahan baku dan biaya total bahan baku yang dihasilkan akan lebih efekti dan efisien sesuai dengan kondisi perusahaan.

\section{DAFTAR PUSTAKA}

Alfatiyah, R. (2017). Perencanaan Produksi Minyak Telon Ukuran 100 Ml Dengan Metode Time Series Di Pt. Merpati Mahardika. Teknik Industri, 9(25).

Bastuti, S., \& Teddy, T. (2017, December). Analisis Persediaan Barang Dengan Metode Time Series Dan Sistem Distribution Requirement Planning Untuk Mengoptimalkan Permintaan Barang Di Pt. Asri Mandiri Gemilang. In Proceedings (Vol. 2, No. 1).

Bastuti, S., Alfatiyah, R., Shobur, M., \& Candra, A. (2019). Manajemen Logistik.

Candra, A. (2019). Pengendalian Persediaan Material Pada Produksi Hot Mix Dengan Pendekatan Metode Economic Order Quantity (Eoq). Jitmi (Jurnal Ilmiah Teknik Dan Manajemen Industri), 1(2), 145-153.
Heizer, Jay, dan Barry Render. 2014. Manajemen Operasi. Edisi Kesebelas. Terjemahan oleh Kurnia Hirson, dkk. 2015. Jakarta: Salemba Empat.

Kurnia, D., Bastuti, S., \& Istiqomah, B. N. (2018). Analisis Pengendalian Bahan Baku Pada Produk Tas Dengan Menggunakan Metode Material Requirements Planning (Mrp) Untuk Meminimalkan Biaya Penyimpanan Di Home Industry Amel Collection. Jitmi (Jurnal Ilmiah Teknik Dan Manajemen Industri), 1(1), 22-28.

Murdifin Haming dan Mahfud Nurnajamudin. 2014. Manajemen Produksi Modern, Operasi Manufaktur dan Jasa. Buku Kesatu, PT. Bumi Aksara, Jakarta.

Russel, R.S dan Taylor, B.W. 2003. Operation Management. Prentice Hall. New Jersey. 